\title{
Hospital and Patient Characteristics Regarding the Place of Death of Hospitalized Impending Death Patients: A Multilevel Analysis
}

\author{
Shin-Ting Yeh ${ }^{1}$, Yee-Yung $\mathrm{Ng}^{2}$ and Shiao-Chi Wu ${ }^{3, *}$ \\ 1 College of Nursing, National Taipei University of Nursing and Health Sciences, Taipei 11221, Taiwan; \\ n2899@ms18.hinet.net \\ 2 Department of Medicine, School of Medicine, Fu Jen Catholic University Hospital, Fu Jen Catholic \\ University, Taipei 24205, Taiwan; yyngscwu12@gmail.com \\ 3 Institute of Health \& Welfare Policy, National Yang-Ming University, No.155, Sec.2, Linong Street, \\ Taipei 11221, Taiwan \\ * Correspondence: scwu@ym.edu.tw; Tel.: +886-2-2826-7052
}

Received: 4 October 2019; Accepted: 16 November 2019; Published: 20 November 2019

\begin{abstract}
Objectives: To explore the influence of hospital and patient characteristics on deaths at home among inpatients facing impending death. Method: In this historical cohort study, 95,626 inpatients facing impending death from 362 hospitals in 2011 were recruited. The dependent variable was the place of death. The independent variables were the characteristics of the hospitals and the patients. A two-level hierarchical generalized linear model was used. Results: In total, $41.06 \%$ of subjects died at home. The hospital characteristics contributed to $29.25 \%$ of the total variation of the place of death. Private hospitals (odds ratio $[\mathrm{OR}]=1.32,95 \%$ confidence interval $[\mathrm{CI}]=1.00-1.75$ ), patients $>65$ years old $(\mathrm{OR}=1.48,95 \% \mathrm{CI} .=1.42-1.54)$, married $(\mathrm{OR}=3.15,95 \% \mathrm{CI} .=2.93-3.40)$ or widowed $(\mathrm{OR}=3.39,95 \% \mathrm{CI} .=3.12-3.67)$, from near-poor households $(\mathrm{OR}=5.16,95 \% \mathrm{CI} .=4.57-5.84)$, having diabetes mellitus ( $\mathrm{OR}=1.79,95 \% \mathrm{CI} .=1.65-1.94)$, and living in a subcounty $(\mathrm{OR}=2.27$, $95 \%$ CI. $=2.16-2.38$ ) were all risk factors for a death at home. Conclusion: Both hospital and patient characteristics have an effect of deaths at home among inpatients facing impending death. The value of the inpatient mortality rate as a major index of hospital accreditation should be interpreted intrinsically with the rate of deaths at home.
\end{abstract}

Keywords: dying; place of death; population register; multilevel analysis; hospital mortality

\section{Introduction}

Because of the clinical competence provided by hospital personnel, dying in hospital is deemed preferable to dying at home for inpatients facing an impending death [1,2]. However, dying at home is considered psychologically more comfortable for patients facing an impending death because it gives family members and friends more time with the person and grants them more autonomy and privacy $[3,4]$. The choice of dying in a familiar environment such as the home is judged reasonable and might even be suggested by doctors [4].

The proportion of people dying at home ranges from $12 \%$ to $60 \%$ [5-13]. A study by Brazil et al. revealed that the rate of at-home deaths was $56 \%$ [14]. The rate of at-home deaths in Japanese patients was approximately $46 \%$ to $67 \%$ [15,16]. Among patients in Singapore, 29\% died at home [17]. Tang et al. reported that the rate of at-home deaths in patients with cancer was approximately $32.4 \%$ to $43.6 \%[18,19]$. Cohen et al. reported a strikingly large variation in the rate of home deaths (from $12 \%$ to $57 \%$ ) in patients with cancer across 14 countries, namely Belgium, Canada, the Czech Republic, 
England, France, Hungary, Italy, Mexico, the Netherlands, New Zealand, South Korea, Spain, the United States, and Wales [20].

In addition to patients' sex, age, education level, marriage status, income, and type of cancer [3,21-29], the accessibility and availability of health care services affect inpatients and their families in their choice between a hospital or an at-home death $[21,25,29,30]$. In Taiwan, the National Health Insurance (NHI) programs cover almost the entire population and reduce financial barriers to receiving medical care. Therefore, we investigated the effect of hospital and inpatient characteristics on the place of death under minimum influence from medical expenses. Whether hospitals play a role in the decision-making process of inpatients choosing an at-home death is of interest. If the lower inpatient mortality rate is due to inpatients who are facing impending death choosing an at-home death, the value of the inpatient mortality rate as a major index of hospital accreditation might be altered $[6,31,32]$.

\section{Methods}

\subsection{Study Cohort and Data Sources}

The national register of deaths, health records of medical facilities, registry of beneficiaries, registry of contracted medical facilities, and inpatient expenditures from the National Health Informatics Project of the Ministry of Health and Welfare were linked using encrypted personal identification numbers and hospital IDs in this retrospective cohort study.

\subsection{Participants and Sampling}

In 2011, 152,030 people ( $0.65 \%$ of the total population) died in Taiwan. After excluding people who died an accidental death, death by suicide or homicide, or before hospitalization, 97,203 people who had been hospitalized the day before their death were selected as inpatients facing impending death. Subsequently, 1577 deaths that occurred in psychiatric hospitals were excluded. Finally, 95,626 inpatients facing impending death from 362 hospitals were included for analysis in the present study. Because the NHI program covers most of the population, the use of national databases with encrypted personal IDs and death certificates prevented selection and participation bias [33].

\subsection{Study Variables}

The dependent variable selected was the place of death (either in hospital or at home). The independent variables included the characteristics of patients and hospitals. The patient characteristics included sex, age $(<18,18-39,40-54,55-64,65-74,75-84, \geqq 85)$, marital status (unmarried, married, divorced, widowed, missing), income (low-income households, near-poor households, moderate-income households, and high-income households), and cause of death (e.g., cancer, diabetes mellitus, heart disease, stroke, disease of the respiratory system, disease of the digestive system, and suicide). When reviewing the patients' places of residence, the urbanization degree was categorized into the following five types: municipality, province, county, subcounty, and rural area. The hospital characteristics included the ownership status (public or private) and the accreditation status of the hospital (medical center, regional hospital, district teaching hospital, and district hospital).

\subsection{Statistical Analysis}

All statistical analyses were performed using the SAS statistical (SAS system for Windows, version 9.3) and HLM 6.06 software packages. Numbers and percentages were used to describe the characteristics of the patients (Level 1) and the hospitals (Level 2).

In the present study, inpatients from the same hospital were likely to be correlated [34]. Therefore, we applied two-level hierarchical generalized linear models (HGLMs) using the Bernoulli sampling method and logit link function to avoid the violation of the assumption of uncorrected errors [35], and to make the study result more robust [3]. At level 1, the characteristics of the patients were included. 
At level 2, the characteristics of the hospitals were included in this study. The model designed in the present study was of random intercept and fixed slope. We assumed that the effect of each patient's factors was the same and the coefficient of each covariate was fixed across hospitals. This model design is a widely used approach in multilevel analyses [3,36].

In the HGLMs, the intraclass correlation coefficient (ICC) measured the proportion of total variance among hospitals [37]. In a normal hierarchical linear model, the estimation of the ICC requires both the random intercept $(\tau 00)$ variance and the residual variance $\left(\sigma^{2}\right)$ : ICC $=\tau 00 /\left(\tau 00+\sigma^{2}\right)$ [37]. However, if an HGLM presents no error term in the logit link function, it means there is no residual variance term $\left(\sigma^{2}\right)$. Therefore, an approximate ICC was calculated assuming that the latent residual term followed a logistic distribution and using the variance of the logistic distribution $\pi 2 / 3=3.29$. Under this model, the ICC was measured as $\tau 00 /[\tau 00+(\pi 2 / 3)]$ where $\pi 2 / 3=3.29$ [38]. In addition, we calculated the $\mathrm{R}^{2}$-type in different models. The $\mathrm{R}^{2}$-type, which was used to represent the explanation of the model, was measured as $[(\mathrm{VN}-\mathrm{VF}) / \mathrm{VN}] \times 100 \%$. VN was the hospital-level variance of the null model, and $\mathrm{VF}$ was the variance of the full model [39].

The multilevel modeling followed a staged approach [40]. In the first stage, we used an unconditional model with no predictors to test for a significant between-hospital variability in the place of death. In the second stage, we included the estimations from several preliminary conditional models. Model 1 included the Level 1 predictors to determine if the effects of any of the Level 1 predictors varied across the study sample. Model 2 included the Level 2 predictors to determine if the effects of any of the Level 2 predictors varied across the study sample. Finally, we included all of the Level 1 and Level 2 predictors in Model 3.

\subsection{Ethical Statement}

This study was approved by the Institutional Review Board of National Yang-Ming University (approval number 99007) in Taiwan. All data sets were analyzed at the Health and Welfare Data Science Center (HWDC) because the results of the data analysis had to be verified by an examiner of the HWDC to ensure the protection of personal data.

\section{Results}

In this study, $60.84 \%$ of patients facing impending death were male, $30.19 \%$ were between 75 and 84 years old, $54.55 \%$ were married, $40.17 \%$ had a moderate income, $35.39 \%$ died of cancer, and $54.73 \%$ lived in a municipality. The patients were recruited at $67.84 \%$ from private hospitals and $32.16 \%$ from public hospitals. Specifically, 36.22\%, $44.21 \%, 4 \%$, and $15.57 \%$ were hospitalized in a medical center, regional hospital, district teaching hospital, and district hospital, respectively. In total, $41.06 \%(39,266$ of 95,626 ) chose to die at home (Table 1 ).

In the bivariate analysis, female patients appeared more likely to choose to die at home than male patients $(43.87 \%$ versus $39.25 \%, p<0.001)$. The choice to die at home was significantly more common in elderly patients than in younger patients (respectively, $47.34 \%, 45.74 \%$, and $39.77 \%$ in the age groups of $65-74$ years old, $75-84$ years old, and $\geqq 85$ years old versus $7.95 \%, 25.91 \%, 30.28 \%$, and $38.98 \%$ in the age groups of $<18$ years old, $18-39$ years old, $40-54$ years old, and 55-64 years old, $p<0.001$ ). The married and widowed patients were more likely to choose to die at home than the unmarried and divorced patients (respectively, $44.44 \%$ and $47.37 \%$ versus $14.01 \%$ and $17.85 \%, p<0.001$ ). Patients from moderate- to high-income households were also more likely to choose to die at home than patients from low-income and near-poor households (respectively, $60.48 \%$ and $38.35 \%$ versus $12.5 \%$ and $21.45 \%$, $p<0.001)$. Patients with diabetes mellitus had a significantly higher rate of at-home deaths than patients with cancer, heart disease, stroke, and respiratory system disease $(51.62 \%$ versus $41.55 \%$, $38.94 \%, 44.78 \%$, and $38.76 \%$, respectively, $p<0.001$ ). Inpatients living in municipalities were less likely to choose to die at home than those living in provinces, counties, subcounties, and rural areas ( $31 \%$ versus $35.38 \%, 40.32 \%, 60.08 \%$, and $51.8 \%$, respectively, $p<0.001$ ). Patients in medical centers, regional hospitals, district teaching hospitals, and district hospitals chose to die at home in $39.24 \%$, 
$45.4 \%, 37.65 \%$, and $33.88 \%$ of cases, respectively. Compared with public hospitals, more inpatients hospitalized in private hospitals chose to die at home $(31.50 \%$ versus $45.59 \%, p<0.001)$ (Table 1$)$.

Table 1. Situation of discharge for inpatients facing impending death in 2011: univariate analysis.

\begin{tabular}{|c|c|c|c|c|c|c|c|}
\hline & \multirow{3}{*}{ Total } & \multirow{3}{*}{$\%$} & \multicolumn{4}{|c|}{ Death Place } & \multirow{3}{*}{$p$ Value } \\
\hline & & & \multicolumn{2}{|c|}{ Hospital } & \multicolumn{2}{|c|}{ Home } & \\
\hline & & & $\mathbf{N}$ & $\%$ & $\mathbf{N}$ & $\%$ & \\
\hline Total & 95,626 & 100.00 & 56,360 & 58.94 & 39,266 & 41.06 & \\
\hline \multicolumn{8}{|l|}{ Patient's characteristics } \\
\hline Gender & & & & & & & $<0.001$ \\
\hline Female & 37,444 & 39.16 & 21,017 & 56.13 & 16,427 & 43.87 & \\
\hline Male & 58,182 & 60.84 & 35,343 & 60.75 & 22,839 & 39.25 & \\
\hline Age & & & & & & & $<0.001$ \\
\hline$<18$ & 679 & 0.71 & 625 & 92.05 & 54 & 7.95 & \\
\hline $18-39$ & 2848 & 2.98 & 2110 & 74.09 & 738 & 25.91 & \\
\hline $40-54$ & 10,848 & 11.34 & 7563 & 69.72 & 3285 & 30.28 & \\
\hline $55-64$ & 13,318 & 13.93 & 8127 & 61.02 & 5191 & 38.98 & \\
\hline $65-74$ & 16,601 & 17.36 & 8742 & 52.66 & 7859 & 47.34 & \\
\hline $75-84$ & 28,867 & 30.19 & 15,663 & 54.26 & 13,204 & 45.74 & \\
\hline$\geqq 85$ & 22,465 & 23.49 & 13,530 & 60.23 & 8935 & 39.77 & \\
\hline Marriage & & & & & & & $<0.001$ \\
\hline Unmarried & 8409 & 8.79 & 7231 & 85.99 & 1178 & 14.01 & \\
\hline Married & 52,168 & 54.55 & 28,982 & 55.56 & 23,186 & 44.44 & \\
\hline Divorce & 5222 & 5.46 & 4290 & 82.15 & 932 & 17.85 & \\
\hline Widow & 29,261 & 30.60 & 15,400 & 52.63 & 13,861 & 47.37 & \\
\hline missing & 566 & 0.59 & 457 & 80.74 & 109 & 19.26 & \\
\hline Income & & & & & & & $<0.001$ \\
\hline Low-income households & 3015 & 3.15 & 2638 & 87.50 & 377 & 12.50 & \\
\hline Near poor households & 30,353 & 31.74 & 23,842 & 78.55 & 6511 & 21.45 & \\
\hline Moderate income & 38,415 & 40.17 & 15,181 & 39.52 & 23,234 & 60.48 & \\
\hline High income & 23,843 & 24.93 & 14,699 & 61.65 & 9144 & 38.35 & \\
\hline Cause of death & & & & & & & $<0.001$ \\
\hline Cancer & 33,841 & 35.39 & 19,781 & 58.45 & 14,060 & 41.55 & \\
\hline Diabetes Mellitus & 4287 & 4.48 & 2074 & 48.38 & 2213 & 51.62 & \\
\hline Heart diseases & 7960 & 8.32 & 4860 & 61.06 & 3100 & 38.94 & \\
\hline Stroke & 6932 & 7.25 & 3828 & 55.22 & 3104 & 44.78 & \\
\hline $\begin{array}{l}\text { Diseases of the } \\
\text { respiratory system }\end{array}$ & 13,982 & 14.62 & 8562 & 61.24 & 5420 & 38.76 & \\
\hline $\begin{array}{c}\text { Diseases of the digestive } \\
\text { system }\end{array}$ & 7530 & 7.87 & 4334 & 57.56 & 3196 & 42.44 & \\
\hline Suicide & 447 & 0.47 & 291 & 65.10 & 156 & 34.90 & \\
\hline Others & 20,647 & 21.59 & 12,630 & 61.17 & 8017 & 38.83 & \\
\hline Urbanization degree & & & & & & & $<0.001$ \\
\hline Municipality & 52,336 & 54.73 & 36,110 & 69.00 & 16,226 & 31.00 & \\
\hline Province & 4113 & 4.30 & 2658 & 64.62 & 1455 & 35.38 & \\
\hline County & 8928 & 9.34 & 5328 & 59.68 & 3600 & 40.32 & \\
\hline subcounty & 27,971 & 29.25 & 11,166 & 39.92 & 16,805 & 60.08 & \\
\hline Rural & 2278 & 2.38 & 1098 & 48.20 & 1180 & 51.80 & \\
\hline \multicolumn{8}{|l|}{ Hospital characteristics } \\
\hline Ownership & & & & & & & $<0.001$ \\
\hline Public & 30,757 & 32.16 & 21,068 & 68.50 & 9689 & 31.50 & \\
\hline private & 64,869 & 67.84 & 35,292 & 54.41 & 29,577 & 45.59 & \\
\hline Accredited Hospital & & & & & & & $<0.001$ \\
\hline Medical center & 34,638 & 36.22 & 21,047 & 60.76 & 13,591 & 39.24 & \\
\hline Regional hospital & 42,277 & 44.21 & 23,085 & 54.60 & 19,192 & 45.40 & \\
\hline District teaching hospital & 3825 & 4.00 & 2385 & 62.35 & 1440 & 37.65 & \\
\hline District hospital & 14,886 & 15.57 & 9843 & 66.12 & 5043 & 33.88 & \\
\hline
\end{tabular}

In the HGLMs, the ICC measured the proportion of total variance that occurs among hospitals [37]. In the null model, the variation among hospitals was 1.36. The ICC was estimated to be $0.2925[1.36 /(1.36$ + 3.29)]. This estimation indicated that the percentage of variation between hospitals was $29.25 \%$ of the total variation. The $\mathrm{R}^{2}$-type in Model 1 was $25.00 \%$ [(1.36-1.02)/1.36 × 100\%], indicating that 
patient characteristics could explain $25.00 \%$ of the variation in the place of death of inpatients facing impending death. The $\mathrm{R}^{2}$-type in Model 2 was 5.15\% [(1.36-1.29)/1.36 $\times 100 \%$ ], indicating that hospital characteristics can explain $5.15 \%$ of the variation in the place of death of inpatients facing impending death. When both patient and hospital characteristics were entered in Model 3, the $\mathrm{R}^{2}$-type was $30.15 \%$ [(1.36-0.95)/1.36 $\times 100 \%]$. This result means that hospital and patient characteristics can explain $30.15 \%$ of the variation in the place of death of inpatients facing impending death (Table 2). Overall, patients $>65$ years old (odds ratio $[\mathrm{OR}]=1.48,95 \%$ confidence interval $[\mathrm{CI}]=1.42-1.54$ ), married $(3.15,2.93-3.40)$ or widowed $(3.39,3.12-3.67)$, from near-poor households $(5.16,4.57-5.84)$, having diabetes mellitus $(1.79,1.65-1.94)$, and living in a subcounty $(2.27,2.16-2.38)$ were more likely to be discharged from hospital after choosing to die at home compared with patients $<65$ years old, unmarried, with a high income, having other diseases (cancer, heart disease, and stroke), and living in a municipality. Compared with public hospitals, inpatients hospitalized in private hospitals were $32 \%$ more likely to be discharged from hospital after choosing to die at home (1.32, 1.00-1.75) (Table 2).

Table 2. Factors affecting the discharge of inpatients facing impending death: two-level hierarchical generalized linear model.

\begin{tabular}{|c|c|c|c|c|c|c|c|c|c|}
\hline & \multicolumn{9}{|c|}{ Two-Level Hierarchical Generalized Linear Model $(N=95,060)^{a}$} \\
\hline & \multicolumn{3}{|c|}{ Model 1} & \multicolumn{3}{|c|}{ Model 2} & \multicolumn{3}{|c|}{ Model 3} \\
\hline & Adj-OR & 95\% C.I. & $p$ Value & Adj-OR & 95\% C.I. & $p$ Value & Adj-OR & 95\% C.I. & $p$ Value \\
\hline Intercept & 0.03 & $(0.02-0.03)$ & $<0.001$ & 0.43 & $(0.25-0.75)$ & $<0.01$ & 0.03 & $(0.02-0.05)$ & $<0.001$ \\
\hline \multicolumn{10}{|l|}{$\begin{array}{l}\text { Patient's characteristics } \\
\text { Gender (Male:0) }\end{array}$} \\
\hline Female & 0.98 & $(0.95-1.02)$ & & & & & 0.98 & $(0.95-1.02)$ & \\
\hline \multicolumn{10}{|l|}{ Age $(<65: 0)$} \\
\hline$\geqq 65$ & 1.47 & $(1.42-1.53)$ & $<0.001$ & & & & 1.48 & $(1.42-1.54)$ & $<0.001$ \\
\hline $\begin{array}{l}\text { Marriage (Unmarried:0) } \\
\text { Married }\end{array}$ & 3.15 & $(2.93-3.40)$ & $<0.001$ & & & & 3.15 & $(2.93-3.40)$ & $<0.001$ \\
\hline Divorce & 1.19 & $(1.08-1.32)$ & $<0.01$ & & & & 1.19 & $(1.08-1.32)$ & \\
\hline Widow & 3.39 & $(3.13-3.67)$ & $<0.001$ & & & & 3.39 & $(3.12-3.67)$ & $<0.001$ \\
\hline \multicolumn{10}{|l|}{ Income (High income:0) } \\
\hline Low-income households & 1.55 & $(1.37-1.76)$ & $<0.001$ & & & & 1.55 & $(1.37-1.76)$ & $<0.001$ \\
\hline Near poor households & 5.17 & $(4.57-5.84)$ & $<0.001$ & & & & 5.16 & $(4.57-5.84)$ & $<0.001$ \\
\hline Moderate income & 3.18 & $(2.81-3.60)$ & $<0.001$ & & & & 3.17 & $(2.80-3.60)$ & $<0.001$ \\
\hline \multicolumn{10}{|l|}{ Cause of death (Others:0) } \\
\hline Cancer & 1.12 & $(1.07-1.17)$ & $<0.001$ & & & & 1.11 & $(1.07-1.16)$ & $<0.001$ \\
\hline Diabetes Mellitus & 1.79 & $(1.65-1.94)$ & $<0.001$ & & & & 1.79 & $(1.65-1.94)$ & $<0.001$ \\
\hline Heart diseases & 0.97 & $(0.91-1.02)$ & & & & & 0.97 & $(0.91-1.03)$ & \\
\hline Stroke & 1.27 & $(1.18-1.35)$ & $<0.001$ & & & & 1.27 & $(1.18-1.35)$ & $<0.001$ \\
\hline $\begin{array}{c}\text { Diseases of the respiratory } \\
\text { system }\end{array}$ & 1.01 & $(0.96-1.06)$ & & & & & 1.01 & $(0.96-1.06)$ & \\
\hline $\begin{array}{c}\text { Diseases of the digestive } \\
\text { system }\end{array}$ & 1.11 & $(1.04-1.19)$ & $<0.01$ & & & & 1.11 & $(1.04-1.18)$ & $<0.01$ \\
\hline Suicide & 0.62 & $(0.50-0.79)$ & $<0.001$ & & & & 0.62 & $(0.50-0.79)$ & $<0.001$ \\
\hline \multicolumn{10}{|l|}{$\begin{array}{l}\text { Urbanization degree } \\
\text { (Municipality:0) }\end{array}$} \\
\hline Province & 1.35 & $(1.22-1.48)$ & $<0.001$ & & & & 1.35 & $(1.22-1.48)$ & $<0.001$ \\
\hline County & 1.55 & $(1.45-1.65)$ & $<0.001$ & & & & 1.55 & $(1.45-1.66)$ & $<0.001$ \\
\hline subcounty & 2.27 & $(2.16-2.38)$ & $<0.001$ & & & & 2.27 & $(2.16-2.38)$ & $<0.001$ \\
\hline Rural & 2.15 & $(1.91-2.41)$ & $<0.001$ & & & & 2.16 & $(1.92-2.42)$ & $<0.001$ \\
\hline \multicolumn{10}{|l|}{$\begin{array}{l}\text { Hospital characteristics } \\
\text { Ownership (Public:0) }\end{array}$} \\
\hline Private & & & & 1.50 & $(1.09-2.07)$ & $<0.05$ & 1.32 & $(1.00-1.75)$ & $<0.05$ \\
\hline $\begin{array}{l}\text { Accredited Hospital } \\
\text { (Medical center:0) }\end{array}$ & & & & & & & & & \\
\hline Regional hospital & & & & 1.44 & $(0.81-2.55)$ & & 1.13 & $(0.69-1.86)$ & \\
\hline District teaching hospital & & & & 0.77 & $(0.38-1.54)$ & & 0.68 & $(0.37-1.24)$ & \\
\hline District hospital & & & & 0.77 & $(0.45-1.33)$ & & 0.66 & $(0.42-1.05)$ & \\
\hline $\begin{array}{c}\text { Variance component of } \\
\text { level } 2\left(\tau_{00}\right)\end{array}$ & 1.02 & & $<0.001$ & 1.29 & & $<0.001$ & 0.95 & & $<0.001$ \\
\hline R square ${ }^{b}(\%)$ & 25.00 & & & 5.15 & & & 30.15 & & \\
\hline
\end{tabular}

Note $^{\text {a: }}$ We excluded the study sample whose marriage status was 'missing'. Finally, there were 95,060 eligible samples for analysis in this study. The reference group of the dependent variable is people who are recorded dying in hospital. The variance component of the null model $(\tau 00)$ is 1.36 . Note ${ }^{b}$ : The R square was calculated by $\left[\left(V_{N}\right.\right.$ $\left.\left.-\mathrm{V}_{\mathrm{F}}\right) / \mathrm{V}_{\mathrm{N}}\right] \times 100 \%$, where $\mathrm{V}_{\mathrm{N}}(1.36)$ was the variance component of level 2 in the null model and the $V_{F}$ was the variance component of level 2 in the full model. 


\section{Discussion}

The study demonstrated that the number of inpatients facing impending death who chose to die at home (41.06\%) was lower than that in previous studies (57.7\% in 2000 and 74.1\% in 1971) [22,41]. This result might be related to the continuous urbanization and social transition in Taiwan. This phenomenon was evidenced by the lower proportion of inpatients living in municipalities choosing to die at home compared with those living in subcounties and rural areas (31\% versus $60.08 \%$ and $51.8 \%$, respectively, OR > 2) (Tables 1 and 2). The limited living space in municipalities, which constrains the coffin-moving process in and out of apartments, might have led to patients and family members accepting an in-hospital death [3,24,41].

In the present study, older people, those who were married or widowed, or were from near-poor households, chose an at-home death, as in previous studies [22,26,30,41-45]. The fact that older patients tend to choose dying at home might be related to the traditional belief that ancestors will lead the deceased from home to the equivalent of paradise for Western monotheist religions. Dying at home does not only take the misfortune away, but it also brings good luck to the descendants [22]. Compared with unmarried and divorced patients, married or widowed patients are more often accompanied by family members [46]. Some studies have indicated that in-hospital deaths are associated with a lower quality and satisfaction, as well as complicated grief for the surviving family members $[13,47,48]$. Dying at home not only alleviates the loneliness of patients but also helps family members express their emotions, which in turn decreases the sorrow at the time of death [26].

The proportion of inpatients with diabetes mellitus facing impending death who chose an at-home death was significantly higher than that of patients with other diseases such as cancer, heart disease, or stroke $(p<0.001)$. This result might be related to their suffering and tiredness from the chronicity and comorbidities of diabetes such as nephropathy, neuropathy, and disability [23,27]. Therefore, patients with diabetes, and their families, tended to choose to die at home when the patients' conditions deteriorated to the impending death stage.

A higher proportion of inpatients facing impending death in private hospitals chose to die at home, compared with public hospitals (1.51 times in Model 2 and 1.32 times in full model) (Table 2). This result indicates that inpatients are more likely to be discharged when they reach a critical condition at private hospitals compared with public hospitals [31,32]. The reason for private hospitals to discharge patients facing impending death might be related to their objective of low inpatient mortality rate, which advertises a better quality of care in terms of hospital accreditation. Although some researchers have considered the hospital standardized mortality ratio (HSMR) as a measure of health care quality, others have pointed out that considering HSMR as a measure of hospital quality leads to a possible skewing in the choice of the place of death. Our study evidenced that the more inpatients facing impending death there were who died at home, the lower the inpatient death rate. Therefore, combining inpatient and home death rates may yield a better index than inpatient death rate alone for the measurement of hospital health care quality.

According to Cohen's definition [49], multilevel analysis is a more efficient method than regression analysis when the ICC is higher than 0.059 . The ICC of 0.2925 in the null model in this study indicated a high degree of clustering in patients' place of death between hospitals. The characteristics of hospitals and patients were associated with the place of death. Therefore, using a two-level (patients and hospitals) analysis to address the place of death was appropriate in this study. The characteristics of patients and hospitals explained $25.00 \%$ and $5.17 \%$ of the choice to die at home among patients facing impending death, respectively. This result indicates that patient characteristics matter more (4.85 times) than hospital characteristics in the choice to die at home. However, hospital characteristics also play a role in the choice to die at home. The effect of hospital characteristics cannot be ignored.

This study had a limitation. Some parameters such as patient preference in place of death, functional status, and family support [50,51] were not included in our data set as other administration data sets did. Theoretically, the functional status of inpatients facing impending death might be similar. Furthermore, the marital status, family income, cause of death, and urbanization degree of the place of 
residence were entered into the model of this study for risk adjustment. Nevertheless, this study had two key strengths. First, inpatients from the same hospital were likely to be correlated. The two-level HGLMs used in this study solved the problem of inpatients' nonindependence. This study not only improved the estimation of effects within patient units but also formulated and tested hypotheses on cross-level effects. In addition, the model partitioned the variance and covariance components among levels [52]. Second, this is the first study to explore the role of patient and hospital characteristics in the choice of death place among inpatients facing impending death. Apart from the patient factors, hospital characteristics played a role in the choice of an at-home death.

\section{Conclusions}

In total, $41.06 \%$ of inpatients facing impending death chose to die at home. The factors influencing the choice to die at home included hospitalization in a private hospital, $>65$ years old, married or widowed status, near-poor household, diabetes mellitus, and place of residence in a subcounty. The at-home death rate influences the inpatient mortality rate. Therefore, the value of the inpatient mortality rate as a major index of hospital accreditation should be interpreted intrinsically with the rate of deaths at home.

Author Contributions: S.-T.Y. and S.-C.W. conceived the conceptualization, methodology, and investigation. S.-T.Y. conceived the formal analysis and the writing of original draft preparation. Y.-Y.N. and S.-C.W. conceived the writing of review and editing. All authors read and approved the final article.

Funding: This research received no external funding.

Acknowledgments: The authors thank to the Taiwan National Health Informatics Project of the Ministry of Health and Welfare for providing the National Health Insurance Research Database.

Conflicts of Interest: The authors declare no conflict of interest.

\section{References}

1. Cancernetwork.com. Dying in Hospital May Be Preferable to Dying at Home. Available online: http:// www.cancernetwork.com/articles/dying-hospital-may-be-preferable-dying-home (accessed on 30 November 2019).

2. Higginson, I.J.; Sarmento, V.P.; Calanzani, N.; Benalia, H.; Gomes, B. Dying at home-Is it better: A narrative appraisal of the state of the science. Palliat. Med. 2013, 27, 918-924. [CrossRef]

3. Gu, D.; Liu, G.; Vlosky, D.A.; Yi, Z. Factors associated with place of death among the Chinese oldest old. J. Appl. Gerontol. 2007, 26, 34-57. [CrossRef]

4. WebMD. Dying at Home: The Basics. Available online: http://www.webmd.com/healthy-aging/questionsanswers-dying-at-home-medref (accessed on 30 November 2019).

5. Gomes, B.; Calanzani, N.; Gysels, M.; Hall, S.; Higginson, I.J. Heterogeneity and changes in preferences for dying at home: A systematic review. BMC Palliat. Care 2013, 12, 7. [CrossRef] [PubMed]

6. Gruneir, A.; Mor, V.; Weitzen, S.; Truchil, R.; Teno, J.; Roy, J. Where people die: A multilevel approach to understanding influences on site of death in America. Med. Care Res. Rev. 2007, 64, 351-378. [CrossRef]

7. Cohen, J.; Bilsen, J.; Addington-Hall, J.; Löfmark, R.; Miccinesi, G.; Kaasa, S.; Onwuteaka-Philipsen, B.; Deliens, L. Population-based study of dying in hospital in six European countries. Palliat. Med. 2008, 22, 702-710. [CrossRef]

8. Cohen, J.; Houttekier, D.; Onwuteaka-Philipsen, B.; Miccinesi, G.; Addington-Hall, J.; Kaasa, S.; Bilsen, J.; Deliens, L. Which patients with cancer die at home? A study of six European countries using death certificate data. J. Clin. Oncol. 2010, 28, 2267-2273. [CrossRef]

9. Currow, D.C.; Burns, C.M.; Abernethy, A.P. Place of death for people with noncancer and cancer illness in South Australia: A population-based survey. J. Alliative Care 2008, 24, 144-150. [CrossRef]

10. Murtagh, F.; Bausewein, C.; Petkova, H.; Sleeman, K.; Dodd, R.; Gysels, M.; Johnston, B.; Murray, S.; Banerjee, S.; Shipman, C. Understanding Place of Death for Patients with Non Malignant Conditions: A Systematic Literature Review; Final report; NIHR Service Delivery and Organisation Programme: Southampton, UK, 2012. 
11. Abel, J.; Pring, A.; Rich, A.; Malik, T.; Verne, J. The impact of advance care planning of place of death, a hospice retrospective cohort study. BMJ Supportive Palliat. Care 2013, 3, 168-173. [CrossRef]

12. Gomes, B.; Higginson, I.J. Where people die (1974-2030): Past trends, future projections and implications for care. Palliat. Med. 2008, 22, 33-41. [CrossRef]

13. Mitchell, S.L.; Teno, J.M.; Miller, S.C.; Mor, V. A national study of the location of death for older persons with dementia. J. Am. Geriatr. Soc. 2005, 53, 299-305. [CrossRef]

14. Brazil, K.; Howell, D.; Bedard, M.; Krueger, P.; Heidebrecht, C. Preferences for place of care and place of death among informal caregivers of the terminally ill. Palliat. Med. 2005, 19, 492-499. [CrossRef] [PubMed]

15. Fukui, S.; Fukui, N.; Kawagoe, H. Predictors of place of death for Japanese patients with advanced-stage malignant disease in home care settings: A nationwide survey. Cancer 2004, 101, 421-429. [CrossRef] [PubMed]

16. Ikezaki, S.; Ikegami, N. Predictors of dying at home for patients receiving nursing services in Japan: A retrospective study comparing cancer and non-cancer deaths. BMC Palliat. Care 2011, 10, 3. [CrossRef] [PubMed]

17. Poulose, J.V.; Do, Y.K.; Neo, P.S.H. Association between referral-to-death interval and location of death of patients referred to a hospital-based specialist palliative care service. J. Pain Symptom Manag. 2013, 46, 173-181. [CrossRef] [PubMed]

18. Tang, S.T.; Huang, E.-W.; Liu, T.-W.; Rau, K.-M.; Hung, Y.-N.; Wu, S.-C. Propensity for home death among Taiwanese cancer decedents in 2001-2006, determined by services received at end of life. J. Pain Symptom Manag. 2010, 40, 566-574. [CrossRef]

19. Ko, M.-C.; Huang, S.-J.; Chen, C.-C.; Chang, Y.-P.; Lien, H.-Y.; Lin, J.-Y.; Woung, L.-C.; Chan, S.-Y. Factors predicting a home death among home palliative care recipients. Medicine 2017, 96, e8210. [CrossRef]

20. Cohen, J.; Pivodic, L.; Miccinesi, G.; Onwuteaka-Philipsen, B.; Naylor, W.; Wilson, D.; Loucka, M.; Csikos, A.; Pardon, K.; Van den Block, L. International study of the place of death of people with cancer: A population-level comparison of 14 countries across 4 continents using death certificate data. Br. J. Cancer 2015, 113, 1397. [CrossRef]

21. Beng, A.; Fong, C.W.; Shum, E.; Goh, C.R.; Goh, K.T.; Chew, S.K. Where the elderly die: The influence of socio-demographic factors and cause of death on people dying at home. Ann. Acad. Med. Singap. 2009, 38, 676-683.

22. Chiu, M.K. Returning Home to Die? Changes in Death Locations and Related Factors, 1971-2000. NCCU J. Sociol. 2006, 38, 25-55.

23. Kelley, A.S.; Ettner, S.L.; Wenger, N.S.; Sarkisian, C.A. Determinants of Death in the Hospital Among Older Adults. J. Am. Geriatr. Soc. 2011, 59, 2321-2325. [CrossRef]

24. Lin, H.C.; Lin, Y.J.; Liu, T.C.; Chen, C.S.; Lin, C.C. Urbanization and place of death for the elderly: A 10-year population-based study. Palliat. Med. 2007, 21, 705-711. [CrossRef] [PubMed]

25. Nakamura, S.; Kuzuya, M.; Funaki, Y.; Matsui, W.; Ishiguro, N. Factors influencing death at home in terminally ill cancer patients. Geriatr. Gerontol. Int. 2010, 10, 154-160. [CrossRef] [PubMed]

26. Chu, S.Y.; Lin, M.H.; Chen, T.J.; Hwang, S.J. Psychosocial and Clinical Factors Associated with Place of Death in Taiwan. Taipei City Med. J. 2008, 5, 484-494.

27. Tang, S.T.; Liu, T.W.; Tsai, C.M.; Wang, C.H.; Chang, G.C.; Liu, L.N. Patient awareness of prognosis, patient-family caregiver congruence on the preferred place of death, and caregiving burden of families contribute to the quality of life for terminally ill cancer patients in Taiwan. Psycho-Oncology 2008, 17, 1202-1209. [CrossRef]

28. Taylor, E.J.; Ensor, B.; Stanley, J. Place of death related to demographic factors for hospice patients in Wellington, Aotearoa New Zealand. Palliat. Med. 2012, 26, 342-349. [CrossRef]

29. Van Rensbergen, G.; Nawrot, T.S.; Van Hecke, E.; Nemery, B. Where do the elderly die? The impact of nursing home utilisation on the place of death. Observations from a mortality cohort study in Flanders. BMC Public Health 2006, 6, 178. [CrossRef]

30. Lin, H.C.; Lin, C.C. A population-based study on the specific locations of cancer deaths in Taiwan, 1997-2003. Support Care Cancer 2007, 15, 1333-1339. [CrossRef]

31. Lee, T.F.; Wu, S.C. The Changes in Mortality Rate in Patients with Coronary Artery Bypass Surgery before and after the Implementation of a Casebased Prospective Payment System. Taiwan J. Public Health 2004, 23, 305-315. 
32. Wu, S.C.; Chien, L.N.; Ng, Y.Y.; Chu, H.F.; Chen, C.C. Association of Case Volume with Mortality of Chinese Patients after Coronary Artery Bypass Grafting Taiwan Experience. Circ. J. 2005, 69, 1327-1332. [CrossRef]

33. Hsing, A.W.; Ioannidis, J.P. Nationwide population science: Lessons from the Taiwan National Health Insurance Research Database. JAMA Intern. Med. 2015, 175, 1527-1529. [CrossRef]

34. Chung, W.; Cho, W.H.; Yoon, C.W. The influence of institutional characteristics on length of stay for psychiatric patients: A national database study in South Korea. Soc. Sci. Med. 2009, 68, 1137-1144. [CrossRef] [PubMed]

35. Robinson, W.S. Ecological correlations and the behavior of individuals. Int. J. Epidemiol. 2009, 38, $337-341$. [CrossRef] [PubMed]

36. Raudenbush, S.W. HLM 6: Hierarchical Linear and Nonlinear Modeling; Scientific Software International: Skokie, IL, USA, 2004.

37. Parish, S.L.; Rose, R.A.; Andrews, M.E.; Shattuck, P.T. Receipt of professional care coordination among families raising children with special health care needs: A multilevel analysis of state policy needs. Child. Youth Serv. Rev. 2009, 31, 63-70. [CrossRef]

38. Browne, W.J.; Subramanian, S.V.; Jones, K.; Goldstein, H. Variance partitioning in multilevel logistic models that exhibit overdispersion. J. R. Stat. Soc. Ser. A (Stat. Soc.) 2005, 168, 599-613. [CrossRef]

39. Snidjers, T.; Bosker, R.J. Multilevel Analysis: An Introduction to Basic and Advanced Multilevel Modeling; Sage: London, UK, 1999.

40. Ben-Zeev, D.; Ellington, K.; Swendsen, J.; Granholm, E. Examining a cognitive model of persecutory ideation in the daily life of people with schizophrenia: A computerized experience sampling study. Schizophr. Bull. 2011, 37, 1248-1256. [CrossRef]

41. Lin, M.H.; Lu, Y.S.; Chen, T.J.; Hwang, S.J. Trends in Place of Death of Cancer Patients in Taiwan. Taiwan J. Hosp. Palliat. Care 2006, 11, 14-23.

42. Burge, F.; Lawson, B.; Johnston, G. Trends in the place of death of cancer patients, 1992-1997. Can. Med. Assoc. J. 2003, 168, 265-270.

43. Costantini, M.; Balzi, D.; Garronec, E.; Orlandini, C.; Parodi, S.; Vercelli, M.; Bruzzi, P. Geographical variations of place of death among Italian communities suggest an inappropriate hospital use in the terminal phase of cancer disease. Public Health 2000, 114, 15-20. [CrossRef]

44. Gomes, B.; Higginson, I.J. Factors influencing death at home in terminally ill patients with cancer: Systematic review. BMJ (Clin. Res. Ed.) 2006, 332, 515-521. [CrossRef]

45. Cabañero-Martínez, M.J.; Nolasco, A.; Melchor, I.; Fernández-Alcántara, M.; Cabrero-García, J. Place of death and associated factors: A population-based study using death certificate data. Eur. J. Public Health 2019, 29, 608-615. [CrossRef]

46. Turner, V.; Flemming, K. Socioeconomic factors affecting access to preferred place of death: A qualitative evidence synthesis. Palliat. Med. 2019, 33, 607-617. [CrossRef] [PubMed]

47. Teno, J.M.; Clarridge, B.R.; Casey, V.; Welch, L.C.; Wetle, T.; Shield, R.; Mor, V. Family perspectives on end-of-life care at the last place of care. JAMA 2004, 291, 88-93. [CrossRef] [PubMed]

48. Wright, A.A.; Keating, N.L.; Balboni, T.A.; Matulonis, U.A.; Block, S.D.; Prigerson, H.G. Place of death: Correlations with quality of life of patients with cancer and predictors of bereaved caregivers' mental health. J. Clin. Oncol. 2010, 28, 4457. [CrossRef]

49. Cohen, J. Statistical Power Analysis for the Behavioral Sciences, 2nd ed.; Erlbaum: Hillsdale, NJ, USA, 1988.

50. Cohen, J.; Bilsen, J.; Miccinesi, G.; Lofmark, R.; Addington-Hall, J.; Kaasa, S.; Norup, M.; van der Wal, G.; Deliens, L. Using death certificate data to study place of death in 9 European countries: Opportunities and weaknesses. BMC Public Health 2007, 7, 283. [CrossRef]

51. Grundy, E.; Mayer, D.; Young, H.; Sloggett, A. Living arrangements and place of death of older people with cancer in England and Wales: A record linkage study. Br. J. Cancer 2004, 91, 907-912. [CrossRef]

52. Raudenbush, S.W.; Bryk, A.S. Hierarchical Linear Models: Applications and Data Analysis Methods; Sage: London, UK, 2002.

(C) 2019 by the authors. Licensee MDPI, Basel, Switzerland. This article is an open access article distributed under the terms and conditions of the Creative Commons Attribution (CC BY) license (http://creativecommons.org/licenses/by/4.0/). 